\title{
Pharmacists' Knowledge and Practice of Issues Related to Using Psychotropic Medication in Elderly People in Ethiopia: A Prospective Cross-Sectional Study
}

\author{
Gashaw Binega Mekonnen $\left.{ }^{1}\right)^{1}$ and Alemante Tafese Beyna ${ }^{2}$ \\ ${ }^{1}$ College of Medicine and Health Science, School of Pharmacy, Department of Clinical Pharmacy, University of Gondar, P.O. Box-196, \\ Gondar, Ethiopia \\ ${ }^{2}$ College of Medicine and Health Sciences, School of Pharmacy, Department of Pharmacology, University of Gondar, Gondar, Ethiopia
}

Correspondence should be addressed to Gashaw Binega Mekonnen; gasbinega@yahoo.com

Received 1 June 2020; Accepted 30 July 2020; Published 12 August 2020

Academic Editor: Nilufer Yuksel

Copyright (C) 2020 Gashaw Binega Mekonnen and Alemante Tafese Beyna. This is an open access article distributed under the Creative Commons Attribution License, which permits unrestricted use, distribution, and reproduction in any medium, provided the original work is properly cited.

\begin{abstract}
Purpose. This study is aimed at assessing pharmacists' knowledge and practice of issue related to usage of psychotropic medications in elderly people, in Gondar town Northwest, Ethiopia. Methods. A cross-sectional study was conducted among pharmacists working in community, health center, and hospital pharmacies in Gondar town from March 1 to May 30, 2020. A total of 73 medication retail outlets (40 pharmacies and 33 drug stores) were included in this study. Pharmacy personnel's knowledge and practice were assessed using self-administered validated questionnaires. Binary and multivariable logistic regression analyses were used to assess the association between different variables. $P<0.05$ was used to declare the association. Result. A total of 144 pharmacists were included in the study; the mean age was 30.13 (SD \pm 5.87 ), ranging from 20 to 55years. The mean knowledge score was 7.789 (SD \pm 2.98$)$, and $75(52.1 \%)$ of them had poor knowledge. The mean practice score was $2.32 \pm 0.912$ (mean $\pm \mathrm{SD}$ ), and $77(53.5 \%)$ of the respondents had poor practice. All participants had not taken on-the-job training about psychotropic medication. Work experience $(P<0.029)$ and personal monthly income $(P<0.046)$ were significantly associated with pharmacists' knowledge. There was a significant association between work experience and practice level $(P<0.043)$. Conclusion. The knowledge and practice of pharmacy personnel were low for issues related to the use of psychotropic medication in the elderly. This result indicates the need for training for pharmacists on pharmacotherapy of psychotropic medication.
\end{abstract}

\section{Introduction}

The elderly are defined by a chronological age of 65 years and older. This population has been and will be steadily increasing and expected to reach $22 \%$ in 2050 [1]. Aging involves progressive impairments in the functional reserve of many organs, which might also affect pharmacodynamics and pharmacokinetics of drugs [2,3]. Elderly people are extremely prone to develop psychiatric morbidities due to aging of the brain, problems with physical health, cerebral pathologies, and a decrease in economic independence and breakdown of the family support system [4-7] because the use of psychotropic medications among elderly patients is high [8-11]. Psychopharmacology in elderly people is quite specific, and the tendency of older people to develop side effects to psychoactive medications is often due to physiological changes associated with aging, altered pharmacokinetics, and pharmacodynamics $[12,13]$. The study report showed that the elderly patients on average took 2 to 5 drugs, and poly-pharmacy occurred in 20$50 \%$ of elderly patients $[2,3]$. Consequently, adverse drug reactions and drug interactions are more common and more serious in the elderly $[14,15]$. Frequent checks of used medications, particularly for drug interactions and 
use of medications, are considered appropriate for the elderly $[12,16]$.

Pharmacists are the most trusted and easily accessible health care practitioners and can play an indispensable role in selecting appropriate medicines, monitoring drug use, including adherence, optimal pharmaceutical care encouraging good health behaviors, and drug-related problems, which is a particular risk for the elderly. Pharmacists also provide appropriate information about interactions between drugs and other substances, including OTC drugs, dietary supplements, and foods [17-21]. Thus, to provide good healthcare services, pharmacists are expecting to have commitment, ethics, adequate knowledge, attitude, and skills of medication [22]. However, different studies have shown that pharmacists have low knowledge and practice related to medication use, including psychotropic medication, particularly in elderly patients $[23,24]$. As in other developing countries, pharmacy practice in Ethiopia is evolving rapidly; however, there is a lack of empirical evidence about pharmacists' knowledge, practice, and experience of medication use [25]. In Ethiopia, nearly half of the pharmacists had an unfavorable attitude toward pharmaceutical care [24]. Thus, research is required to determine the magnitude of pharmacist knowledge and practice regarding psychotropic medication usage in the elderly.

Hence, to the best of the literature search done, no prior study has been conducted in Gondar town, Ethiopia, regarding assessing pharmacy personnel's knowledge and practice of issues related to psychotropic medication in the elderly. Thus, this study is aimed at assessing pharmacists' knowledge and practice of issue related to usage of psychotropic medications in elderly people and the associated factors in Gondar town, Ethiopia.

\section{Method}

2.1. Study Design and Setting. A cross-sectional study was conducted in Gondar town from March 1 to May 30, 2020. Gondar town is under the Amahara regional state of Ethiopia, which is located at $750 \mathrm{Km}$ from Addis Ababa, the capital city of Ethiopia. According to United NationsWorld Population Prospects, the population of Gondar in 2019 was 347,000. Gondar town has one compressive specialized hospital, two primary hospitals, and twelve health centers. There are 40 pharmacies and 33 drug stores currently serving people.

2.2. Inclusion Criteria and Exclusion Criteria. Pharmacy personnel with a diploma and above in pharmacy that works on the community, health center, and hospital pharmacy in Gondar town and willing to complete the study questionnaire were included. However, pharmacy personnel who had work experience of fewer than six months were excluded from the study.

2.3. Sample Size Determination and Sampling Techniques. All pharmacy professionals (155) that met the inclusion criteria were included in the study.
2.4. Study Variables. The dependent variables were pharmacists' knowledge and practice on psychotropic medication usage in the elderly. Independent variables included socioeconomic and demographic characteristics (age, gender, dress/residency, monthly income, marital status, living arrangements, level of education, and work experience) and respondent professional and environmental-related status (graduated collage, current working institution, and course and training towards psychotropic medication.

2.5. Data Collection Method. Data were collected using a structured self-administered questionnaire on 155 pharmacists who gave their consent for participation in the study. The data collection tool was developed after reviewing published literature $[23,26,27]$ and consisted of 37 items that were divided into four sections. Questions 1-8 focused on the sociodemographic characteristics of the respondents, questions 9-13 focused on environmental-related status, and questions 14-32 and questions 33-37 are aimed at assessing the level of knowledge and practice of pharmacists toward psychotropic medication in the elderly, respectively. Respondents had to choose either "true," "false," or "I don't know" for knowledge questions and "Yes" or "No" for practice-related questions. Respondents will award one point for each correct answer and zero point for choosing wrong answer, "I do not know" is included to avoid guessing, and it counts zero point [28]. The final scores were calculated for the 19-statement knowledge test as the percentage correct, which ranged from $0 \%$ to $100 \%$. Participants were considered to have "good knowledge" if they scored $\geq 50 \%$ (score of 10-19) and poor knowledge $<50 \%$ (score of 0-9) [23].

2.6. Data Quality Assurance. The data collection tool was pretested on a 5\% (8) pharmacy professional that was not included in the final analysis, and the questionnaire was sent to three senior pharmacists who were academicians and researchers for face validity, approval was obtained, and some modifications were done.

2.7. Data Analysis. The collected data were cleared, entered into, and analyzed using SPSS version 20.0 for Windows (SPSS Inc., Chicago, IL). The results are described in terms of frequencies, percentages, and means. The relationships among variables were analyzed using Pearson's chi-square test. Then, a bivariate analysis was carried out to evaluate the crude effect of each independent variable on the different study outcomes. Variables with a $P$ value less than or equal to 0.2 in the bivariate analysis were included in multivariate logistic regression models. $P<0.05$ was considered significant.

2.8. Ethical Clearance. Ethical clearance was taken from the Ethical Review Committee of the School of Pharmacy, College of Medicine and Health Sciences, University of Gondar, and verbal consent was obtained from the head of each pharmacy and participants.

2.9. Operational Definition. Good knowledge is the knowledge status of pharmacy personnel when they scored $\geq 50 \%$ [29]. Low knowledge is the knowledge status of pharmacy 
TABLE 1: Sociodemographic characteristics of pharmacy personnel in Gondar town, Ethiopia, April 2020, $N=144$.

\begin{tabular}{lc}
\hline Variable & Frequency $(\%)$ \\
\hline Age & \\
$18-30$ & $73(50.7)$ \\
$30-40$ & $65(45.1)$ \\
$>40$ & $6(4.2)$ \\
Gender & \\
$\quad$ Male & $79(54.9)$ \\
Female & $65(45.1)$ \\
Residence & \\
Urban & $127(88.2)$ \\
$\quad$ Rural & $17(11.8)$ \\
Marital status & \\
Single & $67(46.5)$ \\
Married & $77(53.5)$ \\
Living arrangement & \\
Alone & $55(38.2)$ \\
With family or relative & $89(61.8)$ \\
Level of education & \\
Pharmacy technician & $77(53.5)$ \\
Degree and above in pharmacy & $67(46.5)$ \\
Work experience & \\
$\quad<5$ years & $76(52.8)$ \\
Personal monthly income (birr) & $68(47.2)$ \\
$\quad$ 5000 & \\
\hline & \\
& \\
&
\end{tabular}

when they scored $<50 \%$ [29]. Good practice is the practice status of pharmacy personnel when they score $\geq$ mean. Low practice is the practice status of pharmacy personnel when they score $<$ mean.

\section{Result}

3.1. Sociodemographic and Professional-Related Characteristics of the Respondents. Of the 155 questionnaires, 144 were adequately filled and returned, resulting in a response rate of $92.9 \%$. Among the 144 respondents, 79 (54.9\%) were male. The mean age of the respondents was $30.13 \pm 5.87$ (mean $\pm \mathrm{SD}$ ), ranging from 20 to 55years; 73 (50.7\%) of participants were in the age group 18-30 years old, and $77(53.5 \%)$ of the respondents were married. Majority, 89 (61.8\%), of the respondents were living with family or relative, 77 (53.5\%) respondents were pharmacy technicians and $76(52.8 \%)$ and $78(54.2 \%)$ of the respondents had less than 5 years of professional work experience and less than 5 thousand birr monthly income, respectively (presented in Table 1).

3.2. Environmental-Related Status. A majority of 83 (57.6\%) respondents were graduated from government institutions, and $82(56.9 \%)$ of the respondents worked on government
TABLE 2: Pharmacy personnel's professional and environmentalrelated status in Gondar town, Ethiopia, April 2020, $N=144$.

\begin{tabular}{lc}
\hline Variable & Frequency (\%) \\
\hline Graduated college & $83(57.6)$ \\
Government & $61(42.4)$ \\
Private & \\
Current working institution & $82(56.9)$ \\
$\quad$ Government & $62(43.1)$ \\
Private & \\
Practice setting & $60(41.7)$ \\
Hospital & $23(16)$ \\
Health center & $61(42.4)$ \\
Community pharmacy & \\
Had you take a course on psychotropic \\
medication during pharmacy \\
learning program \\
$\quad$ Yes \\
No \\
Have you ever take training about \\
psychotropic medication after graduation \\
Yes \\
No
\end{tabular}

institutions. Regarding the practice setting, 61 (42.4\%) of the respondents worked on community pharmacies. Moreover, all respondents were taking a course on psychotropic medication during the pharmacy learning program, and all of them had not taken on-the-job training about psychotropic medication (summarized in Table 2).

3.3. Pharmacist's Knowledge of Psychotropic Medication Usage in Elderly Patients. One hundred two (70.8\%) of the respondents knew that the dose of antipsychotics or benzodiazepines should be reduced in elderly people due to altered metabolism rates and higher sensitivity. 35 (24.3\%) respondents response that low-dose hypnosedative medications given over the short term might reverse the physiological changes in sleep patterns in elderly people. And 55 (38.2\%) knew the recommended daily dose of risperidone.

Regarding pharmacists' knowledge about the selection of appropriate medications, 66 (45.8\%) respondents knew the preferences of antipsychotics over benzodiazepine for sedating elderly patients with severe agitation or delirium. In addition, $58(40.3 \%)$ of them knew that antipsychotic medications reduce symptoms such as delusions and hallucinations.

Regarding knowledge about side effects, 73 (50.7\%) respondents knew that the use of hypnosedative can lead to physical and emotional dependence. Only 56 (38.9\%) of them knew long-term (3 months or above) intake of antipsychotic medications increases the risk of cerebrovascular accidents. Half of the respondents (72 (50\%) of them) knew that benzodiazepines can lead to side effects in the old like confusion, memory, and concentration disorders, as shown in Table 3. 
TABle 3: Pharmacy personnel's knowledge on psychotropic medication used in elderly people, Gondar, Ethiopia, April $2020, N=144$.

\begin{tabular}{|c|c|c|c|c|}
\hline \multirow{2}{*}{\multicolumn{2}{|c|}{ Statement }} & \multicolumn{3}{|c|}{ Response } \\
\hline & & True & False & I do not know \\
\hline \multicolumn{5}{|c|}{ Statement related to dosage } \\
\hline 1 & $\begin{array}{l}\text { Due to changed metabolism and a higher sensitivity, } \\
\text { older persons need a lower dose of antipsychotics or } \\
\text { benzodiazepines in order to get the same effect. }\end{array}$ & $102(70.8)$ & $23(16)$ & $19(13.2)$ \\
\hline 2 & $\begin{array}{l}\text { The recommended daily dosage of olanzapine is } 50 \text { to } 100 \mathrm{mg} \\
\text { in older people with severe behavioral disorders in dementia. }\end{array}$ & $83(57.6)$ & $49(34)$ & $12(8.3)$ \\
\hline 3 & $\begin{array}{l}\text { The recommended daily dose of risperidone is } 0.5 \text { to } 2 \mathrm{mg} \\
\text { in older people with severe behavioral disorders in dementia. }\end{array}$ & $55(38.2)$ & $30(20.8)$ & $59(41)$ \\
\hline 4 & $\begin{array}{c}\text { Ageing is associated with physiological changes in the } \\
\text { sleeping pattern. To reverse these changes in the sleep pattern, } \\
\text { hypnosedative medications may be used in low dose } \\
\text { during a short period. }\end{array}$ & $35(24.3)$ & $41(28.5)$ & $68(47.2)$ \\
\hline \multicolumn{5}{|c|}{ Statements related to selection of appropriate medications } \\
\hline 5 & $\begin{array}{c}\text { With the exception of delirium tremens, antipsychotics are } \\
\text { preferred above benzodiazepines for sedating older } \\
\text { patients with severe agitation or delirium. }\end{array}$ & $66(45.8)$ & $34(23.6)$ & $44(30.6)$ \\
\hline 6 & $\begin{array}{c}\text { Antipsychotic medications can have a place } \\
\text { in the treatment of delirium. }\end{array}$ & $60(41.7)$ & $24(16.7)$ & $60(41.7)$ \\
\hline 7 & $\begin{array}{c}\text { Antipsychotic medications reduce such symptoms } \\
\text { as delusions and hallucinations. }\end{array}$ & $58(40.3)$ & $23(16)$ & $63(43.8)$ \\
\hline 8 & $\begin{array}{l}\text { In the care of older adults with dementia, antipsychotic } \\
\text { medications are preferred over behavior-oriented therapy. }\end{array}$ & $50(34.7)$ & $24(16.7)$ & $70(48.6)$ \\
\hline 9 & $\begin{array}{c}\text { Only in severe cases of sleeplessness and failure of alternative therapies } \\
\text { with proven effectiveness, hypnosedatives can be administrated } \\
\text { for a short period of time in the old. }\end{array}$ & $54(37.5)$ & $22(15.3)$ & $68(47.2)$ \\
\hline 10 & $\begin{array}{l}\text { The effects of diazepam, a benzodiazepine, can last for a long } \\
\text { time, making it not proper to use in this age category. }\end{array}$ & $51(35.4)$ & $54(37.5)$ & $39(27.1)$ \\
\hline 11 & $\begin{array}{l}\text { Next to nonpharmacological therapies, hypnosedatives are to be used } \\
\text { for treatment and minimization of the symptoms of anxiety disorders. }\end{array}$ & $55(38.2)$ & $43(29.9)$ & $46(31.9)$ \\
\hline \multicolumn{5}{|c|}{ Statement related to side effect } \\
\hline 12 & Use of hypnosedatives can lead to physical and emotional dependency. & $73(50.7)$ & $10(6.9)$ & $61(42.4)$ \\
\hline 13 & $\begin{array}{l}\text { Long-term ( } 3 \text { months or above) intake of antipsychotic } \\
\text { medications increases the risk for cerebrovascular accidents }\end{array}$ & $56(38.9)$ & $22(15.3)$ & $66(45.8)$ \\
\hline 14 & $\begin{array}{l}\text { Antipsychotic medications can cause side effects in the old such } \\
\text { as disorientation, urine retention, dry mouth, and blurred vision. }\end{array}$ & $62(43.1)$ & $19(13.2)$ & $63(43.8)$ \\
\hline 15 & $\begin{array}{l}\text { Long-term intake ( } 3 \text { months or above) of atypical antipsychotic } \\
\text { medications can lead to an increase in weight. }\end{array}$ & $59(41)$ & $30(20.8)$ & $55(38.2)$ \\
\hline 16 & $\begin{array}{l}\text { Patients starting on antipsychotic medication } \\
\text { are susceptible to postural hypotension. }\end{array}$ & $47(32.6)$ & $36(25)$ & $61(42.4)$ \\
\hline 17 & $\begin{array}{l}\text { One of the side effects of haloperidol is akathisia, which } \\
\text { manifests with constant pacing and restlessness. }\end{array}$ & $60(41.7)$ & $19(13.2)$ & $65(45.1)$ \\
\hline 18 & $\begin{array}{c}\text { There is a connection between long-term ( } 3 \text { months or above) } \\
\text { intake of antipsychotic medications and the } \\
\text { prevalence of falls in the old. }\end{array}$ & $59(41)$ & $22(15.3)$ & $63(43.8)$ \\
\hline 19 & $\begin{array}{l}\text { Benzodiazepines can lead to side effects in the old like } \\
\text { confusion, memory, and concentration disorders. }\end{array}$ & $72(50)$ & $16(11.1)$ & $56(38.9)$ \\
\hline
\end{tabular}

Values are represented as numbers (\%), and correct answers are in boldface.

Regarding the knowledge level of respondents, the overall knowledge score of the respondents ranged from 0 to 19 , with a mean knowledge score of $7.789(\mathrm{SD}=2.98)$ out of the 19 knowledge questions. 75 (52.1\%) of them had poor knowledge, while 69 (47.9\%) of them had good knowledge levels, as presented in Figure 1.
The mean score for level of practice was $2.32 \pm 0.912$ (mean \pm SD) out of 5 practice questions. 77 (53.5\%) of the respondents had poor practice. Study participants who scored less than the mean value were regarded as low practice, whereas participants who scored more than the mean value were regarded as good practice (presented in Figure 2). 


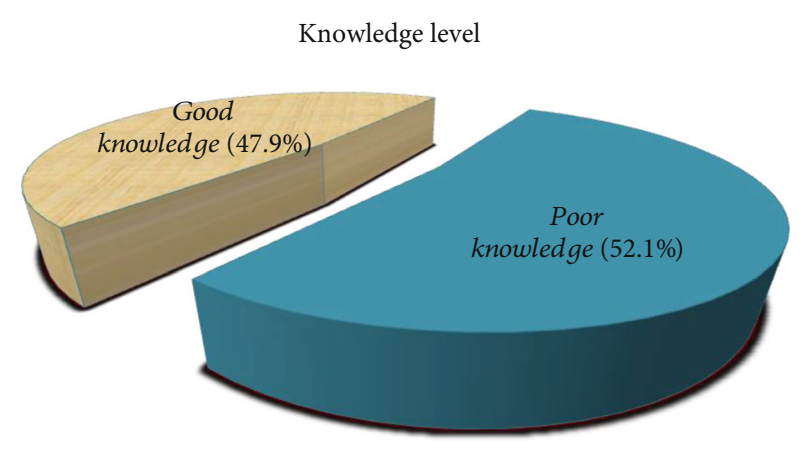

Figure 1: Pharmacy personnel knowledge level on psychotropic medication used in elderly people in Gondar, Ethiopia, April 2020, $N=144$.

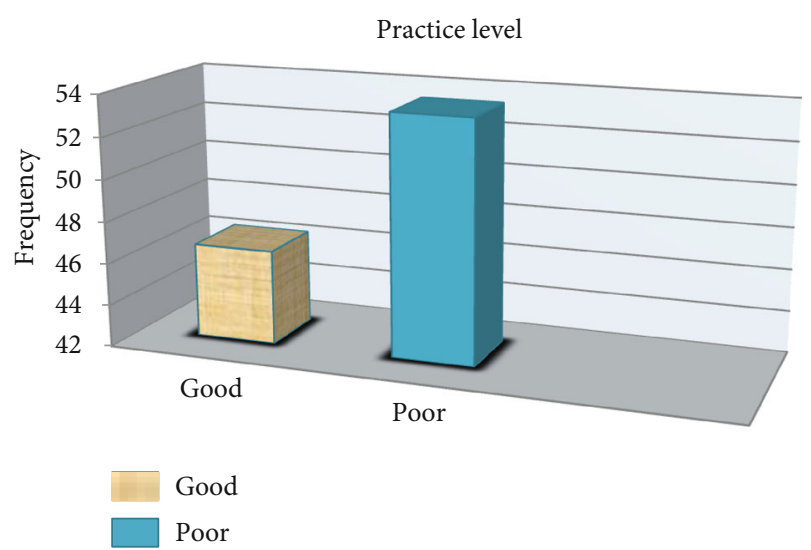

FIgURe 2: Practice level of pharmacy personnel toward psychotropic medication used in elderly people in Gondar, Ethiopia, April 2020, $N=144$.

$122(84.7 \%)$ respondents advice to elderly customers on psychotropic medication, but only 45 (31.3\%) of them dispense psychotropic medication to the elderly with confidence. In the use of valid reference, 28 (19.4\%) pharmacists practice when it is necessary. In addition, 69 (47.9\%) of the respondents advise the elderly about the dosage and administration of psychotropic medications (presented in Figure 3).

3.4. Association between Knowledge and Sociodemographic Characteristics. Accordingly, in the multivariate logistic analysis, pharmacy personnel who had work experiences greater than or equal to 5 years were 4.1 times more likely to have good knowledge than those who had less than 5 years of work experience (AOR, 4.173; 95\% CI, 1.156-15.062; $P<0.029$ ). Pharmacy personnel with a monthly income greater than 5000 birr were 2.7 times more likely to have good knowledge than those with a monthly income less than 5000 birr (AOR, 2.763; 95\% CI, 1.020-7.487; $P<0.046$ ) (summarized in Table 4.

3.5. Association between Practice and Sociodemographic Characteristics. Table 5 indicates that there was a statistically significant association between work experiences and practice level (AOR, 3.725; 95\% CI, 1.040-13.349; $P<0.043$ ).
Concerning age, marital status, practice setting, and other sociodemographic characteristics were not significantly associated.

\section{Discussion}

Medication use during the elderly period is common, and prevalence continues to increase $[30,31]$. Pharmacy professionals must carefully appraise the potential risks of medication use versus risks for the elderly. They should provide patients with information regarding both benefits and risks of medication use while also discussing the limitations of available knowledge so that the elderly will be empowered to make informed decisions that are best for them. Pharmacy personnel have great potential to modify and optimize drug therapy in the elderly [32].

The findings of this study showed that 75 (52.1\%) of the respondents had poor knowledge. This finding was of comparably higher values than the study conducted in Palestine (37.93\%) [23]. This difference might be due to curriculum differences in the country and gaps in on-the-job training. This poor knowledge could be attributed to the fact that participants did not receive any training about psychotropic medication. This fact highlights the importance of on-thejob training of pharmacists and emphasizes the role of the Ministry of Health in improving the performance of pharmacists and expanding their role in managing patients beyond dispensing medications through continuing education. On the other hand, the finding of this study is lower than study done on antiepileptic medication in Khartoum, Sudan, $85.3 \%$ [29].

Concerning the knowledge of pharmacy personnel on the dosage of psychotropic medications (Table 3, statements 14), $102(70.8 \%)$ of the pharmacists knew that the dose of antipsychotics or benzodiazepines should be reduced in elderly people due to altered metabolism rates and higher sensitivity. Of these, 55 (38.2\%) knew the recommended daily dose of risperidone in elderly people with severe behavioral disorders in dementia, and also, 35 (24.3\%) of them knew that lowdose hypnosedative medications given over the short term might reverse the physiological changes in sleep patterns in elderly people. However, only 49 (34\%) correctly answered the statement on the recommended daily dosage of olanzapine in older people with severe behavioral disorders in dementia. In general, in this study, participants gave less correct answers than in the study done in Belgium [33]. This might be due to differences in profession and acquired training.

The findings of this study showed that none of the respondents had attended training about psychotropic medication. Recently, it has been reported that practical training programs increased learning motivation among pharmacy students [34]. Incorporating practical sessions in pharmacology and pharmacotherapy might have positive effects on pharmacists' knowledge, attitudes, and skills [35]. Similarly, using computer simulations have been shown to enhance knowledge of medications and pharmacology [36].

In the present study, the selection of appropriate psychotropic medications (Table 3, statements 5-11) has an average 


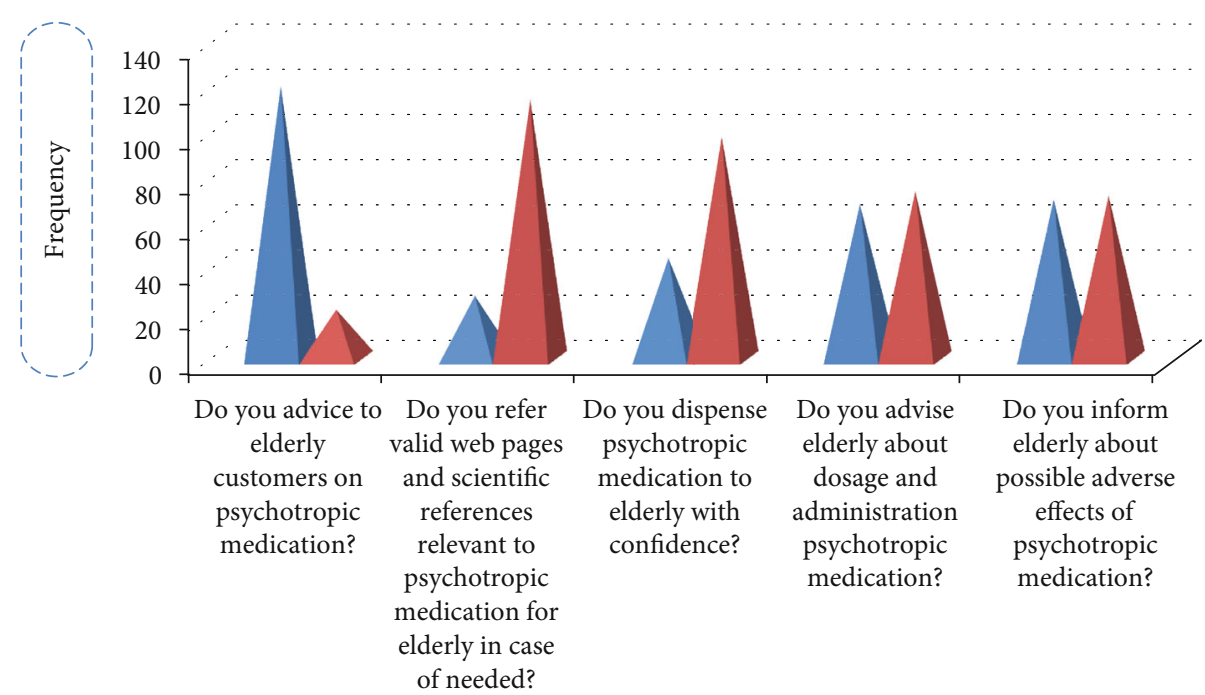

Good

Poor

FIGURE 3: Practice-related response frequency of pharmacy personnel toward psychotropic medication used in elderly people in Gondar, Ethiopia, April 2020, $N=144$.

TABLE 4: Association between sociodemographic characteristics and knowledge level of pharmacy personnel toward psychotropic medication used in elderly people, Gondar, Ethiopia, April 2020, $N=144$.

\begin{tabular}{|c|c|c|c|c|c|}
\hline \multirow{2}{*}{ Variable } & \multicolumn{5}{|c|}{ Total knowledge score } \\
\hline & Good knowledge & Poor knowledge & COR $(95 \% \mathrm{CI})$ & AOR (95\% CI) & $P$ value \\
\hline Age & & & & & 0.245 \\
\hline$<30$ & 28 & 45 & $1^{* *}$ & $1^{* *}$ & \\
\hline $30-40$ & 38 & 27 & $1.607(0.303-8.524)$ & $0.249(0.28-2.217)$ & \\
\hline$>40$ & 3 & 3 & $0.711(0.133-3.792)$ & $0.700(0.104-4.694)$ & \\
\hline Marital status & & & & & 0.348 \\
\hline Single & 23 & 44 & $1^{* *}$ & $1^{* *}$ & \\
\hline Married & 46 & 31 & $2.839(1.439-5.601)$ & $1.493(0.647-3.447)$ & \\
\hline Level of education & & & & & 0.656 \\
\hline Pharmacy technician & 27 & 50 & $1^{* *}$ & $1^{* *}$ & \\
\hline B. Pharm & 42 & 25 & $3.111(1.574-6.149)$ & $1.245(0.475-3.268)$ & \\
\hline Graduated college & & & & & 0.555 \\
\hline Government & 48 & 35 & $1^{* *}$ & $1^{* *}$ & \\
\hline Private & 21 & 40 & $0.383(0.193-0.759)$ & $0.775(0.332-1.809)$ & \\
\hline Work experience & & & & & $0.029^{*}$ \\
\hline$<5$ years & 25 & 51 & $1^{* *}$ & $1^{* *}$ & \\
\hline$\geq 5$ years & 44 & 24 & $3.740(1.876-7.456)$ & $4.173(1.156-15.062)$ & \\
\hline Monthly income (birr) & & & & & $0.046^{*}$ \\
\hline$<5000$ & 24 & 54 & $1^{* *}$ & $1^{* *}$ & \\
\hline$\geq 5000$ & 45 & 21 & $4.821(2.378-9.775)$ & $2.763(1.020-7.487)$ & \\
\hline Practice setting & & & & & 0.133 \\
\hline Hospital & 36 & 24 & $3.429(1.227-9.579)$ & $2.750(0.850-8.897)$ & \\
\hline Health center & 7 & 16 & $2.019(0.979-4.165)$ & $0.857(0.336-2.184)$ & \\
\hline Community pharmacy & 26 & 35 & $1^{* *}$ & $1^{* *}$ & \\
\hline
\end{tabular}

${ }^{* *}$ Constant, ${ }^{*}$ significant. 
TABLE 5: Association between sociodemographic characteristics and practice level of pharmacy personnel toward psychotropic medication used in elderly people, Gondar, Ethiopia, April 2020, $N=144$.

\begin{tabular}{|c|c|c|c|c|c|}
\hline \multirow{2}{*}{ Variable } & \multicolumn{5}{|c|}{ Total practice score } \\
\hline & GP & $\mathrm{PP}$ & COR (95\% CI) & $\operatorname{AOR}(95 \% \mathrm{CI})$ & $P$ value \\
\hline Age & & & & & 0.127 \\
\hline$<30$ & 29 & 44 & $1^{* *}$ & $1^{* *}$ & \\
\hline $30-40$ & 36 & 29 & $0.759(0.130-4.414)$ & $0.123(0.013-1.141)$ & \\
\hline$>40$ & 2 & 4 & $0.403(0.69-2.356)$ & $0.362(0.052-2.509)$ & \\
\hline Marital status & & & & & 0.805 \\
\hline Single & 26 & 41 & $1^{* *}$ & $1^{* *}$ & \\
\hline Married & 41 & 36 & $1.796(1.024-3.882)$ & $0.898(0.381-2.115)$ & \\
\hline Level of education & & & & & 0.210 \\
\hline Pharmacy technician & 26 & 52 & $1^{* *}$ & $1^{* *}$ & \\
\hline B. Pharm & 41 & 26 & $3.093(1.565-6.115)$ & $1.836(0.710-4.744)$ & \\
\hline Graduated college & & & & & 0.058 \\
\hline Government & 49 & 34 & $1^{* *}$ & $1^{* *}$ & \\
\hline Private & 18 & 43 & $0.290(0.144-0.587)$ & $0.448(0.195-1.028)$ & \\
\hline Work experience & & & & & $0.043^{*}$ \\
\hline$<5$ years & 26 & 50 & $1^{* *}$ & $1^{* *}$ & \\
\hline$\geq 5$ years & 41 & 27 & $2.920(1.481-5.756)$ & $3.725(1.040-13.349)$ & \\
\hline Monthly income (birr) & & & & & 0.359 \\
\hline$<5000$ & 26 & 52 & $1^{* *}$ & $1^{* *}$ & \\
\hline$\geq 5000$ & 41 & 25 & $3.280(1.654-6.506)$ & $1.599(0.587-4.361)$ & \\
\hline Current working institution & & & & & 0.632 \\
\hline Government & 42 & 40 & $1^{* *}$ & $1^{* *}$ & \\
\hline Private & 25 & 37 & $0.644(0.330-1.254)$ & $0.519(0.035-7.596)$ & \\
\hline Practice setting & & & & & 0.259 \\
\hline Hospital & 35 & 25 & $3.200(1.147-8.926)$ & $2.466(0.780-7.792)$ & \\
\hline Health center & 7 & 16 & $2.016(0.978-4.157)$ & $0.489(0.033-7.202)$ & \\
\hline Community pharmacy & 25 & 36 & $1^{* *}$ & $1^{* *}$ & \\
\hline
\end{tabular}

${ }^{* *}$ Constant; * significant; GP: good practice; PP: poor practice.

score of 39.08\%. Again, the pharmacy personnel in this study performed worse than Belgian nurses [33]. This may be due to sociodemographic and environment-related differences in respondent and curriculum differences between countries. Pharmacy as a profession is growing. Pharmacists are often consulted by physicians in selecting the most appropriate medications for patients [37]. Therefore, pharmacists' knowledge should be optimized. Failing to do this might have severe negative consequences on the health care system. Many pharmacy schools have realized this and revised their pharmacy curricula accordingly in an attempt to acquaint pharmacy graduates with an optimal level of knowledge [38].

This finding showed that the performance of pharmacy personnel on statements related to side effects (Table 3, statements 12-19) was relatively better than a statement related to dosage and selection of appropriate psychotropic medication.

Of the pharmacists, $73(50.7 \%)$ knew that hypnosedatives can lead to physical and emotional dependence; 62 (43.1\%) knew that antipsychotics are associated with anticholinergic side effects; 59 (41\%) knew that atypical antipsychotics can lead to weight gain; 72 (50\%) knew that benzodiazepines have side effects in the elderly like confusion, memory, and concentration disorders; 60 (41.7\%) knew that haloperidol was associated with akathisia, and antipsychotics increased the prevalence of falls; $47(32.6 \%)$ knew that antipsychotics cause postural hypotension; and 56 (38.9\%) knew that antipsychotics increased the risk of cerebrovascular accidents. The finding of this study has lower value $(42.37 \%)$ than that of the study done by Belgium nurses (56.57\%) [33]. This might be due to the fact that our country has a low-quality controlling system in pharmacy personnel, and less concern is given by the government to improve knowledge of pharmacy personnel. However, there is a higher value with a study done by American community pharmacists regarding donepezil adverse effects [39]. Despite gaps in knowledge, as experts on medications, pharmacists need to be knowledgeable about side effects and drug-drug interactions, including those of psychotropic medications. If well acquainted, pharmacists can play a prominent role in resolving medication-related problems [40-42]. Pharmacists' 
inability to alert patients of the potential side effects of psychotropic medications might severely impact the health of the patients $[43,44]$.

In the present study, about $122(84.7 \%)$ claimed that they advise elderly customers on psychotropic medication. 28 (19.4\%) of them used reference to psychotropic medication, $45(31.3 \%)$ of them dispense with confidence, and 69 (47.9) and 71 (49.3) of them advise the elderly about the dosage and inform the elderly about the possible adverse effects, respectively. In general, from the findings of this study, 77 $(53.5 \%)$ of them had a poor level of practice. This might be due to their knowledge level. As we can see in Figure 1, 75 (52.1\%) of them had poor knowledge, which may have led to their poor practice. This finding was in agreement with another study conducted on dietary supplement knowledge, attitude, and practice of pharmacists in Tehran, which revealed that majority of them had poor practice, and there were positive and significant relationships between level of practice and knowledge [26].

In the present study, pharmacy personnel having work experience $\geq 5$ years (AOR, 4.173; 95\% CI, 1.156-15.062 and AOR, 3.725; 95\% CI, 1.040-13.349) were significantly associated with knowledge and practice level, respectively. This may be because as the number of experiences increases the chance of working with different teams, learning from personal mistakes, and increasing practical skills, these have a positive impact on knowledge level. This finding was in agreement with previous studies done on medication use $(P<0.001)$ in Utha and Qatar $[45,46]$. However, a study conducted on antiepileptic medication in Palestinian pharmacists reported that there was no significant association $(P=0.249)$ between work experience and level of knowledge [28].

In this study, respondents with monthly income $>5000$ birr were significantly associated (AOR, 2.763; 95\% CI, $1.020-7.487$ ) with their knowledge level than having $\leq 5000$ birr personal monthly income. The majority of those getting $\geq 5000$ birr per month might have a higher chance of getting information from social media than a person getting $\leq 5000$ birr. However, contrary to our findings, the study done in Mekele, Ethiopia [47], showed that no significant association between monthly income and knowledge (AOR, 4.411; 95\% CI 0.577-33.712) on generic medication knowledge of pharmacy personnel practicing in Mekele [47].

4.1. Strengths and Limitations of the Study. To the best of the literature search done, this is the first study to assess pharmacists' knowledge and practice regarding issues related to usage of psychotropic medication in elderly people in Ethiopia, so this study can provide baseline information.

However, there were some limitations with the present study. The possible limitation is that the sample size is small to give representative and powered data on associated factors for pharmacist's knowledge and practice, and this is conducted only in Gondar town. Therefore, studies should be conducted with a large sample size at multiple sites. The use of this tool could have underestimated or overestimated the knowledge of pharmacists, as their performance could have been different if the test was based on multiple-choice questions. The test included questions in the form of statements. The respondents' performance could have been different if case-based scenarios were included in the test. The study was assessed using only a quantitative method. Moreover, this is a cross-sectional study design, whereby claims about the directionality of a causal relationship between the dependent and independent variables cannot be verified.

\section{Conclusion}

The knowledge and practice of pharmacy personnel were low towards issues related to the use of psychotropic medication in the elderly. This study revealed that knowledge of pharmacy personnel regarding issues related to the use of psychotropic medication in the elderly was strongly associated with work experience and personal monthly income.

In addition, this practice is also associated with work experience. Further investigation is needed to reveal the reasons which led to this knowledge gap. This issue needs attention from the government in order to provide optimal care. This gap can be improved by providing education and training to practicing pharmacy personnel by organizing continuing medical education programs focused on pharmacotherapy of psychotropic medication.

\section{Data Availability}

The data used to support the findings of this study are available from the corresponding author upon request.

\section{Conflicts of Interest}

All authors declared that they have no conflict of interest.

\section{Authors' Contributions}

The authors of this manuscript made substantial contributions to conception and design, acquisition of data, or analysis and interpretation of data and took part in drafting and revising the article.

\section{References}

[1] United Nations, World population ageing 2013, Department of Economic and Social Affairs PD, 2013.

[2] A. Kennerfalk, A. Ruigómez, M. A. Wallander, L. Wilhelmsen, and S. Johansson, "Geriatric drug therapy and healthcare utilization in the United Kingdom," Annals of Pharmacotherapy, vol. 36, no. 5, pp. 797-803, 2016.

[3] R. Pizzuti, B. Caffari, N. Binkin, and Gruppo ARGENTO, "Prescription drugs and the elderly: results of the Argento study," Igiene e sanita pubblica, vol. 62, no. 1, pp. 11-26, 2006.

[4] A. Dey, Aging in India: Situational Analysis and Planning for the Future. Ministry of Health and Family Welfare, Ramko Press, New Delhi, 2003.

[5] K. M. Schneider, B. E. O’Donnell, and D. Dean, "Prevalence of multiple chronic conditions in the United States' Medicare population," Health and Quality of Life Outcomes, vol. 7, no. 1, p. $82,2009$. 
[6] C. Vogeli, A. E. Shields, T. A. Lee et al., "Multiple chronic conditions: prevalence, health consequences, and implications for quality, care management, and costs," Journal of General Internal Medicine, vol. 22, no. S3, pp. 391-395, 2007.

[7] R. Chrzan, A. Karmowski, M. Pawelec, K. J. Latkowski, and M. Karmowski, "Depression in women aged 75-89, predisposing factors and preventive measures," Advances in Clinical and Experimental Medicine, vol. 21, no. 1, pp. 69-73, 2012.

[8] M. Ćurković, K. Dodig-Ćurković, A. P. Erić, K. Kralik, and N. Pivac, "Psychotropic medications in older adults: a review," Psychiatria Danubina, vol. 28, no. 1, pp. 13-24, 2016.

[9] J. Téllez-Lapeira, J. López-Torres Hidalgo, N. García-Agua Soler, L. Gálvez-Alcaraz, F. Escobar-Rabadán, and A. GarcíaRuiz, "Prevalence of psychotropic medication use and associated factors in the elderly," The European Journal of Psychiatry, vol. 30, no. 3, pp. 183-194, 2016.

[10] M. T. Lornstad, M. Aarøen, S. Bergh, J. Š. Benth, and A. S. Helvik, "Prevalence and persistent use of psychotropic drugs in older adults receiving domiciliary care at baseline," BMC Geriatrics, vol. 19, no. 1, p. 119, 2019.

[11] R. R. Aparasu, J. R. Mort, and H. Brandt, "Psychotropic prescription use by community-dwelling elderly in the United States," Journal of the American Geriatrics Society, vol. 51, no. 5, pp. 671-677, 2003.

[12] M. J. Ruscin, "Drug therapy in the elderly," in The Merck Manual, 3090-3098, R. S. Porter and J. L. Kaplan, Eds., Merck, Sharp \& Dohme Corp., 2011.

[13] C. Simon, H. Everitt, and F. Van Dorp, Oxford Handbook of General Practice, Oxford University Press, Oxford, 2010.

[14] American Geriatrics Society 2015 Beers Criteria Update Expert Panel, "American Geriatrics Society 2015 updated beers criteria for potentially inappropriate medication use in older adults," Journal of the American Geriatrics Society, vol. 63, no. 11, pp. 2227-2246, 2015.

[15] V. Shetty, M. N. Chowta, N. Chowta K, A. Shenoy, A. Kamath, and P. Kamath, "Evaluation of potential drug-drug interactions with medications prescribed to geriatric patients in a tertiary care hospital," Journal of Aging Research, vol. 2018, Article ID 5728957, 6 pages, 2018.

[16] R. S. Porter and J. L. Kaplan, Eds., "RW: Approach to the geriatric patient," in The Merck Manual, 3070-3088, Merck, Sharp \& Dohme Corp., 2011.

[17] J. Lee, S. Alshehri, H. Kutbi, and J. Martin, "Optimizing pharmacotherapy in elderly patients: the role of pharmacists," Integrated Pharmacy Research \& Practice, vol. 4, p. 101, 2015.

[18] H. A. M. Al Rahbi, R. M. Al-Sabri, and H. R. Chitme, "Interventions by pharmacists in out-patient pharmaceutical care," Saudi pharmaceutical journal, vol. 22, no. 2, pp. 101-106, 2014.

[19] K. C. Readdean, A. J. Heuer, and J. Scott Parrott, "Effect of pharmacist intervention on improving antidepressant medication adherence and depression symptomology: a systematic review and meta-analysis," Research in Social \& Administrative Pharmacy, vol. 14, no. 4, pp. 321-331, 2018.

[20] R. L. Barkin, "Pharmacist's evolving role in the nonopioid, over-the-counter, analgesic selection process," American Journal of Therapeutics, vol. 22, no. 6, pp. 423-430, 2015.

[21] T. H. A. M. Vinks, T. C. G. Egberts, T. M. de Lange, and F. H. P. de Koning, "Pharmacist-based medication review reduces potential drug-related problems in the elderly," Drugs \& Aging, vol. 26, no. 2, pp. 123-133, 2009.
[22] D. L. Laven, "A review on specialization in pharmacy-part II: a commentary on postgraduate training and pharmaceutical care," Journal of Pharmacy Practice, vol. 15, no. 6, pp. 504514, 2016.

[23] R. Shawahna, M. Khaskiyyi, H. Abdo, Y. Msarwe, R. Odeh, and S. Salame, "Palestinian pharmacists' knowledge of issues related to using psychotropic medications in older people: a cross-sectional study," Journal of Educational Evaluation for Health Professions, vol. 14, 2017.

[24] A. Tuha, Y. Gurbie, and H. G. Hailu, "Evaluation of knowledge and practice of pharmacy professionals regarding the risk of medication use during pregnancy in Dessie town, northeast Ethiopia: a cross-sectional study," Journal of pregnancy, vol. 2019, Article ID 2186841, 8 pages, 2019.

[25] K. M. Mishore, A. N. Mekuria, A. Tola, and Y. Ayele, "Assessment of knowledge and attitude among pharmacists toward pharmaceutical care in eastern Ethiopia," BioMed Research International, vol. 2020, Article ID 7657625, 7 pages, 2020.

[26] G. Mehralian, N. Yousefi, F. Hashemian, and H. Maleksabet, "Knowledge, attitude and practice of pharmacists regarding dietary supplements: a community pharmacy-based survey in Tehran," Iranian Journal of Pharmaceutical Research, vol. 13, no. 4, pp. 1457-1465, 2014.

[27] K. Perehudoff, M. Azermai, M. Wauters et al., “The psychotropic education and knowledge test for nurses in nursing homes: striving for PEAK performance," Aging \& Mental Health, vol. 20, no. 11, pp. 1182-1189, 2015.

[28] R. Shawahna, A. Atrash, A. Jebril, A. Khalaf, E. Shaheen, and H. Tahboosh, "Evaluation of pharmacists' knowledge of women's issues in epilepsy: a cross-sectional study in Palestinian pharmacy practice," Seizure, vol. 46, pp. 1-6, 2017.

[29] M. A. O. Ali, E. A. A. Mahgoub, M. Nimir, and K. M. Ali, "Knowledge of pharmacists about anti-epileptic drugs in a developing country," Current Drug Safety, vol. 15, no. 1, pp. 32-37, 2020.

[30] F. Jafari, A. Khatony, and E. Rahmani, "Prevalence of selfmedication among the elderly in Kermanshah-Iran," Global Journal of Health Science, vol. 7, no. 2, pp. 360-365, 2015.

[31] C. J. Charlesworth, E. Smit, D. S. H. Lee, F. Alramadhan, and M. C. Odden, "Polypharmacy among adults aged 65 years and older in the United States: 1988-2010," Journals of Gerontology Series A: Biomedical Sciences and Medical Sciences, vol. 70, no. 8, pp. 989-995, 2015.

[32] T. Reilly, D. Barile, and S. Reuben, "Role of the pharmacist on a general medicine acute care for the elderly unit," The American Journal of Geriatric Pharmacotherapy, vol. 10, no. 2, pp. 95-100, 2012.

[33] M. Wauters, M. Azermai, K. Perehudoff, K. Versluys, E. Steeman, and M. Petrovic, "Development and validation of the Psychotropic Education and Knowledge (PEAK) test on psychotropic drugs for nurses in an acute geriatric care setting," European Geriatric Medicine, vol. 7, no. 2, pp. 135-141, 2016.

[34] S. Yamamura and R. Takehira, "Effect of practical training on the learning motivation profile of Japanese pharmacy students using structural equation modeling," Journal of Educational Evaluation for Health Professions, vol. 14, 2017.

[35] P. R. Shankar, N. Jha, O. Bajracharya, S. B. Gurung, and K. K. Singh, "Feedback on and knowledge, attitude, and skills at the end of pharmacology practical sessions," Journal of Educational Evaluation for Health Professions, vol. 8, 2011. 
[36] C. C. Ezeala, A. A. Ram, and N. Vulakouvaki, "Learning gain of pharmacy students after introducing guided inquiry learning with computer simulation in a pharmacology class in Fiji," Journal of Educational Evaluation for Health Professions, vol. 10, 2013.

[37] P. A. Gheewala, G. M. Peterson, C. M. Curtain, P. S. Nishtala, P. J. Hannan, and R. L. Castelino, "Impact of the pharmacist medication review services on drug-related problems and potentially inappropriate prescribing of renally cleared medications in residents of aged care facilities," Drugs \& Aging, vol. 31, no. 11, pp. 825-835, 2014.

[38] M. U. Khan, A. Ahmad, K. Hussain, A. Salam, Z.-u. Hasnain, and I. Patel, "The need for redesigned pharmacy practice courses in Pakistan: the perspectives of senior pharmacy students," Journal of Educational Evaluation for Health Professions, vol. 12, 2015.

[39] M. Marvanova and P. Henkel, "Community pharmacists' knowledge regarding donepezil averse effects and self-care recommendations for insomnia for persons with $\mathrm{AD}$," Pharmacy, vol. 5, no. 4, p. 42, 2017.

[40] K. L. Pellegrin, E. Lee, R. Uyeno, C. Ayson, and R. Goo, "Potentially preventable medication-related hospitalizations: a clinical pharmacist approach to assessment, categorization, and quality improvement," Journal of the American Pharmacists Association, vol. 57, no. 6, pp. 711-716, 2017.

[41] M. Smith, D. W. Bates, T. Bodenheimer, and P. D. Cleary, "Why pharmacists belong in the medical home," Health Affairs, vol. 29, no. 5, pp. 906-913, 2010.

[42] A. S. Boşnak, N. Birand, Ö. Diker, A. Abdi, and B. Başgut, “The role of the pharmacist in the multidisciplinary approach to the prevention and resolution of drug-related problems in cancer chemotherapy," Journal of Oncology Pharmacy Practice, vol. 25, no. 6, pp. 1312-1320, 2018.

[43] N. Yalçin, S. Ak, Ş. C. Gürel, and A. Çeliker, "Compliance in schizophrenia spectrum disorders: the role of clinical pharmacist," International Clinical Psychopharmacology, vol. 34, no. 6, pp. 298-304, 2019.

[44] G. G. Cacciatore, "Pharmacist's duty to warn," American Journal of Hospital Pharmacy, vol. 51, no. 22, pp. 2824-2826, 1994.

[45] P. A. Rouf, B. Thomas, W. Elkassem et al., "Knowledge and practice characteristics of pharmacists in Qatar towards medication use in pregnancy: a cross-sectional survey," Eastern Mediterranean Health Journal, vol. 24, no. 2, pp. 137-145, 2018.

[46] W. R. Doucette, T. Mays-Holland, H. Memmott, and A. G. Lipman, "Cancer pain management: pharmacist knowledge and practices," Journal of Pharmaceutical Care in Pain \& Symptom Control, vol. 5, no. 3, pp. 17-31, 2010.

[47] Y. B. Belay, T. T. Kassa, F. S. Teni, F. T. Dinkashe, A. G. Kassa, and A. G. Welie, "Assessment of knowledge, attitude and practice of pharmacy professionals toward generic medicines, Northern Ethiopia, Mekelle: a cross sectional study," Journal of Basic and Clinical Pharmacy, vol. 8, no. 4, pp. 193-199, 2017. 